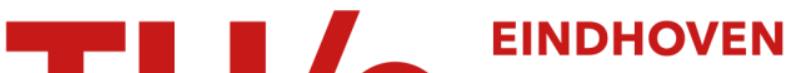

\section{Surface segregation of polydimethylsiloxane-polyether block copolymers in coatings driven by molecular architecture}

\section{Citation for published version (APA):}

Govers, S. P. W., Alexander, N., Al-Masri, M., Omeis, J., van der Ven, L. G. J., de With, G., \& Esteves, A. C. C. (2021). Surface segregation of polydimethylsiloxane-polyether block copolymers in coatings driven by molecular architecture. Progress in Organic Coatings, 150, [105991]. https://doi.org/10.1016/j.porgcoat.2020.105991

\section{Document license: \\ TAVERNE}

DOI:

10.1016/j.porgcoat.2020.105991

\section{Document status and date:}

Published: 01/01/2021

\section{Document Version:}

Publisher's PDF, also known as Version of Record (includes final page, issue and volume numbers)

\section{Please check the document version of this publication:}

- A submitted manuscript is the version of the article upon submission and before peer-review. There can be important differences between the submitted version and the official published version of record. People interested in the research are advised to contact the author for the final version of the publication, or visit the $\mathrm{DOI}$ to the publisher's website.

- The final author version and the galley proof are versions of the publication after peer review.

- The final published version features the final layout of the paper including the volume, issue and page numbers.

Link to publication

\section{General rights}

Copyright and moral rights for the publications made accessible in the public portal are retained by the authors and/or other copyright owners and it is a condition of accessing publications that users recognise and abide by the legal requirements associated with these rights.

- Users may download and print one copy of any publication from the public portal for the purpose of private study or research.

- You may not further distribute the material or use it for any profit-making activity or commercial gain

- You may freely distribute the URL identifying the publication in the public portal.

If the publication is distributed under the terms of Article 25fa of the Dutch Copyright Act, indicated by the "Taverne" license above, please follow below link for the End User Agreement:

www.tue.nl/taverne

Take down policy

If you believe that this document breaches copyright please contact us at:

openaccess@tue.nl

providing details and we will investigate your claim. 


\title{
Surface segregation of polydimethylsiloxane-polyether block copolymers in coatings driven by molecular architecture
}

\author{
Stefan P.W. Govers ${ }^{\mathrm{a}}$, Nicky Alexander ${ }^{\mathrm{a}}$, Majdi Al-Masri ${ }^{\mathrm{b}}$, Jürgen Omeis ${ }^{\mathrm{c}}$, Leendert G. \\ J. van der Ven ${ }^{\mathrm{a}}$, Gijsbertus de With ${ }^{\mathrm{a}}$, A. Catarina C. Esteves ${ }^{\mathrm{a}, *}$ \\ ${ }^{a}$ Laboratory of Physical Chemistry, Department of Chemical Engineering and Chemistry, Eindhoven University of Technology, P.O. Box 513, 5600 MB Eindhoven, the \\ Netherlands \\ ${ }^{\mathrm{b}}$ BYK-Chemie GmbH, Abelstraße 45, 46483 Wesel, Germany \\ c ALTANA AG, Abelstraße 43, 46483 Wesel, Germany
}

\section{A R T I C L E I N F O}

\section{Keywords:}

Surface segregation

Polymer coating

Block copolymer

Polydimethylsiloxane

Polyether

XPS

\begin{abstract}
A B S T R A C T
Block copolymers containing polydimethylsiloxane (PDMS) and poly(ethylene oxide) (PEO) or poly(propylene oxide) (PPO) with varying molar masses were synthesized in a three-step pathway. The functional homopolymer blocks and final diblock copolymers were characterised using proton Nuclear Magnetic Resonance $\left({ }^{1} \mathrm{H}\right.$ NMR) and Matrix Assisted Laser Desorption/Ionization Time of Flight Mass Spectroscopy (MALDI-ToF-MS). These polymers were then incorporated in an industrially relevant solvent-borne coating formulation. Using X-ray Photoelectron Spectroscopy (XPS) and a combination of angle-resolved and depth profiling measurements, concentration profiles of the block copolymer in the top few nanometres of the cured coating were obtained. These amphiphilic molecules were found to be extremely surface active, and high levels of PDMS enrichment of the coating surface were observed at only minimal concentrations. The extent of segregation is sensitive to the exact mass of both the siloxane and polyether block, where an increase in the size of either part resulted in an overall decrease in surface enrichment. PDMS-PPO was found to be more compatible with the coating network than PDMS-PEO, as evidenced by the substantial lower surface enrichment of the former. The surface properties of the liquid and cured films were additionally characterised using surface tension and water contact angle measurements, which largely confirmed the trends observed with XPS. The characterisation of the complex and dynamic processes occurring during drying of the coating is key to provide the ability to effectively tune specific coating systems for required surface properties relevant for individual applications.
\end{abstract}

\section{Introduction}

Coatings provide a robust and versatile approach to functionalize or protect surfaces. Nonetheless, applied liquid films are highly sensitive to various external and internal factors and a broad range of defects may spontaneously form, many of which can be detrimental to the final coating functionality and appearance. Among those the most persistent are surface defects (e.g. poor levelling, crater formation or the orange peel effect) which originate from local surface tension differences in the applied film. [1,2]

It is well known that polymer surfaces can be functionalized by blending with a low amount of amphiphilic block copolymer, where segregation of the low surface energy block imparts significant changes in surface properties. [3-5] High levels of surface enrichment were achieved by block copolymers containing polydimethylsiloxane (PDMS) in a variety of different polymer matrices [6-21]. Analogous block copolymers can also be utilized in crosslinked polymer network coating materials in a similar manner [22,23] as their low surface energy and inherent interfacial affinity results in the possibility to modify coating surface properties with only a minimal bulk concentration [24]. At higher concentrations of the low surface energy polymer, self-stratification may occur and result in a layered and sometimes phase-separated material [25]. Precursors for these systems are often chosen in such a way that the low surface energy component becomes a constituent part of the network, where the extent of surface segregation can be additionally directed using specific curing conditions [26]. A self-stratification approach is generally also beneficial when surface properties of a material need to be changed considerably, i.e. when

\footnotetext{
* Corresponding author.

E-mail address: a.c.c.esteves@tue.nl (A.C.C. Esteves).
} 
partial surface coverage by a small segregating component is insufficient. For example, a self-stratified layer of PDMS was found to provide various robust polyurethane networks with excellent fouling-release properties [27-32]. Crosslinked networks obtained from segmented copolymers containing PDMS and polyurethane, polyurea, or epoxide-based blocks were also successfully employed for these applications due to the preferential positioning of PDMS segments at the coating surface [33-37].

The versatility in block copolymer chemical structures and architectures accessible presents a plethora of handles to steer surface functionality towards a specific application and allows for compatibility with a wide array of different coating systems [1,38-40]. Typical block copolymers of interest for surface energy reduction of an applied film are comprised of a polysiloxane (e.g. PDMS) and a polyether block. Originally designed in the 1960s for the stabilization of polyurethane foams [41-44], these amphiphilic polymers nowadays find their use in a wide number of applications and industrial processes [24,45], among which their employment in coating formulations as levelling components [1, 38-40]. Despite their effectiveness, little fundamental knowledge on the influence of specific block copolymer characteristics on its surface segregation, interfacial affinity and bulk assembly is available which limits their efficient use.

Thorstenson [46] and co-workers investigated the surface concentration of four related silicone-polyether block copolymers in various coating systems. They were able to obtain concentration profiles of the surface-active polymer near both the film-air and film-substrate interface using quantitative Attenuated Total Reflectance Fourier Transform Infrared Spectroscopy (ATR-FTIR) with varying incidence angle. From their results the authors concluded that polymer surfactant/coating compatibility, interfacial tension and mechanism of film formation all show a strong influence on block copolymer surface segregation. However, depth resolution with this method was limited to micrometre-scale and prevented detailed visualization of the block copolymer distribution in the topmost $(<10 \mathrm{~nm})$ surface layers. Yokoyama et al. [47-49] used Neutron Reflectometry (NR) to investigate crosslinked PDMS films containing amphiphilic copolymers of PDMS and poly(ethylene oxide) (PEO). These authors concluded that, when the surface is brought in contact with water, block copolymers segregate to the interface and result in the formation of a dynamic PEO brush. NR measurements could clearly differentiate the layered surface structure and provide detailed information about the brush chain conformation and grafting density. By use of a thermoresponsive hydrophilic analogue, brush thickness and density could be directed further. [50] In a similar approach, Grunlan [51-54] and co-workers imparted silicone surfaces with anti-fouling properties by making use of a siloxane-tethered PEO chain. Chemical crosslinking of the amphiphilic chain in turn provided improved stability of the functional layer.

X-ray Photoelectron Spectroscopy (XPS) can also provide surface characterization with nanometre-scale resolution [55]. The high surface sensitivity of (angle-resolved) XPS has been utilized by several research groups to elucidate the near-surface concentration profiles of PDMS-containing block copolymers added to both polymer films $[6,10$, 11,56] and coating systems [57-59]. More recently, this characterisation method has also been employed to obtain concentration depth profiles of end-fluorinated polymer surfactants in homopolymer films [60-64] and to characterise the surface composition of various fluorinated siloxanes blended in a PDMS matrix [65-67]. The combination of excellent surface and depth resolution with angle-resolved XPS analysis allows for the direct assessment of block copolymer segregation behaviour in the topmost coating surface layers with the ability to discern minor concentration differences.

Here we report on the surface activity and segregation of a series of well-defined polydimethylsiloxane- $b$-poly(ethylene oxide) (PDMS-PEO) and polydimethylsiloxane- $b$-poly(propylene oxide) (PDMS-PPO) block copolymers in an industrially relevant solvent-borne polymer coating formulation. The synthesis and molecular characterisation of these amphiphilic macromolecules is discussed and the relations between block copolymer characteristics, binder compatibility and resulting surface affinity is studied. The results obtained provide new insights in the complex behaviour of these coating components. Understanding the effect of specific interactions between the binder, block copolymers, solvent and other components in the formulation and eventually the processes that occur during coating drying are key to characterise these complex and dynamic mixtures. Detailed insight into these factors will provide the ability to effectively perform optimization studies of specific coating systems and allow for precise tuning of required surface properties relevant for specific applications.

\section{Experimental}

\subsection{Materials}

Hexamethylcyclotrisiloxane $\left(\mathrm{D}_{3} ; 98 \%\right)$, acetic anhydride (99\%), 2,6-di-tert-butyl-4-methylphenol (BHT; $99.0 \%$ ), platinum(0)-1,3divinyl-1,1,3,3-tetramethyldisiloxane (Karstedt's catalyst; $2 \mathrm{wt} \% \mathrm{Pt}$ in xylene), methanesulfonic acid (99.0\%), xylene (mixture of isomers), butyl acetate (HPLC $99.7 \%$ ) and potassium trifluoroacetate (KTFA; 99.0 $\%)$ were purchased from Sigma-Aldrich and used as received. n-Butyllithium (n-BuLi; $1.6 \mathrm{M}$ in hexanes), dimethylchlorosilane (DMCS; $98 \%$ ) and 2,4,6-trihydroxyacetophenone (THAP; $98 \%$ ) were also obtained from Sigma-Aldrich and stored at $5{ }^{\circ} \mathrm{C}$. Cyclohexane (HPLC) and tetrahydrofuran (THF; extra dry) were obtained from Biosolve (The Netherlands) and stored under $3 \AA$ molecular sieves. Poly(ethylene oxide)- and poly(propylene oxide) monoallyl ether (allyl-PEO, allylPPO; molar mass 500, 900 and $1300 \mathrm{~g} \cdot \mathrm{mol}^{-1}$ ) were kindly supplied by BYK-Chemie GmbH, Germany and used as received. Macrynal ${ }^{\circledR}$ SM 515/70BAC was provided by Allnex Germany GmbH, Desmodur ${ }^{\circledR}$ N 75 BA was kindly supplied by Covestro Deutschland AG and stored under inert atmosphere.

\subsection{PDMS-PE block copolymer synthesis}

\subsubsection{PDMS-H synthesis}

Mono silane-terminated polydimethylsiloxane (PDMS-H) was synthesized as reported by Jaunky et al. [68] $\mathrm{D}_{3}$ was dried in a desiccator (drying agent phosphorous pentoxide) for $24 \mathrm{~h}$ before use and all glassware was dried in an oven at $100{ }^{\circ} \mathrm{C}$ for at least $14 \mathrm{~h}$. n-BuLi initiated the polymerization of $\mathrm{D}_{3}$ in cyclohexane and THF, followed by endcapping with DMCS. Workup of the resulting product was done as described by Maschke et al. [69] via removal of the solvent in vacuo at $100{ }^{\circ} \mathrm{C}$ and filtration of the liquid polymer.

\subsubsection{Allyl-PE acetylation}

The acetylation of poly(ethylene oxide) monoallyl ether (allyl-PE) with a molar mass of $900 \mathrm{~g} \cdot \mathrm{mol}^{-1}$ is given as an example. In a $150 \mathrm{~mL}$ three-head flask with condenser, $42.5 \mathrm{~g}(50 \mathrm{mmol})$ allyl-PEO $900-\mathrm{OH}$ was dissolved in $49.2 \mathrm{~mL}$ (42.5 g) xylene. To this mixture $0.043 \mathrm{~g}(0.05$ $\mathrm{wt} \%) \mathrm{BHT}$ and $0.032 \mathrm{~mL}(0.01 \mathrm{~mol}$ equivalent with respect to PE hydroxyl) methanesulfonic acid was added and the solution was subsequently heated to $80^{\circ} \mathrm{C}$ under a dry argon flow. Thereafter, $7.56 \mathrm{~mL}$ (1.6 mol equivalent with respect to $\mathrm{PE}$ hydroxyl) acetic anhydride was added dropwise and the mixture was stirred at $90{ }^{\circ} \mathrm{C}$ for $4 \mathrm{~h}$, after which the product (allyl-PE-Ac) was obtained following removal of solvent and reaction by-products in vacuo at $130{ }^{\circ} \mathrm{C}$.

\subsubsection{PDMS - PE hydrosilylation}

In a $150 \mathrm{~mL}$ three-head flask with condenser, PDMS-H and allyl-PEAc of the desired molar mass were mixed in equal molar ratio silane and allyl functional groups, and dissolved in xylene to prepare a $50 \mathrm{wt} \%$ solution. This mixture was heated to $75{ }^{\circ} \mathrm{C}$ after which $0.05 \mathrm{wt} \%$ Karstedt's catalyst ( $2 \mathrm{wt} \% \mathrm{Pt}$ in xylene) was added. The reaction temperature was increased to $100{ }^{\circ} \mathrm{C}$ and the mixture was stirred for $2 \mathrm{~h}$, after 
which it was filtered. Finally, the solvent was removed in vacuo at 130 ${ }^{\circ} \mathrm{C}$.

For block copolymers containing poly(propylene oxide) (PPO) as the polyether segment, a purification step was introduced to decrease the relatively large content of (diacetylated) PPO using centrifugation and additional extraction in water. In a $250 \mathrm{~mL}$ glass jar, $10 \mathrm{~g}$ of PDMS-PPO block copolymer was mixed with $100 \mathrm{~g}$ water (milliQ) and stirred intensively for $3 \mathrm{~h}$ at room temperature. The mixture was then centrifuged in a Sigma 3-30KS at 15,000 RPM for $2 \mathrm{~h}$ at room temperature. Afterwards, the top phase was manually separated and dried in an oven at $100{ }^{\circ} \mathrm{C}$ for $3 \mathrm{~h}$ to remove remaining traces of water.

\subsubsection{Coating preparation}

The preparation of a liquid coating formulation with a $0.1 \mathrm{wt} \%$ bulk surfactant concentration is given as an example. In a glass vial, $0.050 \mathrm{~g}$ PDMS-PE block copolymer was dissolved in $10.00 \mathrm{~g}$ butyl acetate and stirred for $30 \mathrm{~min}$. Thereafter, $9.00 \mathrm{~g}$ (60 wt\%) Macrynal ${ }^{\circledR}$ SM 515/ 70BAC (hydroxy-functional acrylic resin, $70 \mathrm{wt} \%$ in butyl acetate) was combined with $3.00 \mathrm{~g}(20 \mathrm{wt} \%)$ Desmodur ${ }^{\circledR} 75$ BA (aliphatic polyisocyanate (HDI biuret), $75 \mathrm{wt} \%$ in butyl acetate) and $3.00 \mathrm{~g}$ (20 wt\%) of the block copolymer solution in a $50 \mathrm{~mL}$ glass jar to prepare a coating mixture with an NCO:OH ratio of approximately 1 . The liquid formulation was mixed using an IKA T25 Ultra-Turrax with an outer rotor diameter of $18 \mathrm{~mm}$ at 10,000 RPM for $3 \mathrm{~min}$ and subsequently left to rest for at least $1 \mathrm{~h}$. A $127 \times 76 \mathrm{~mm}^{2} \mathrm{Q}$-Lab aluminum substrate (Cr pretreated) was cleaned with ethanol and the liquid coating formulation was applied using an Erichsen quadruple film applicator with a $90 \mu \mathrm{m}$ gap clearance, at a speed of $10 \mathrm{~mm} \mathrm{~s}^{-1}$ on an Erichsen Coatmaster 509 MC. The applied films were immediately put in an enclosed chamber with a volume of approximately $1.5 \mathrm{dm}^{3}$, which was continuously flushed with a dry nitrogen flow $\left( \pm 150 \mathrm{~L} \mathrm{~h}^{-1}\right.$ at 1 bar), and cured at room temperature for $24 \mathrm{~h}$ followed by a post-cure step at $100^{\circ} \mathrm{C}$ for $1 \mathrm{~h}$. The cured films were subsequently taken out of the chamber and dried in a vacuum oven at $60{ }^{\circ} \mathrm{C}$ for $3 \mathrm{~h}$ to remove any last traces of solvent. Two panels were coated from each liquid formulation.

\subsection{Characterisation techniques and procedures}

The chemical structure, purity and number average molar mass $M_{\mathrm{n}}^{\mathrm{NMR}}$ of all products were determined using proton Nuclear Magnetic Resonance Spectroscopy $\left({ }^{1} \mathrm{H}\right.$ NMR), carried out on a Bruker Varian 400 (400 MHz). Approximately $10 \mathrm{mg}$ of material was dissolved in $0.7 \mathrm{~mL}$ deuterated chloroform using tetramethylsilane (TMS) as reference. The molar mass of PDMS-H was calculated using the ratio of the peak integrals associated with relaxation of the terminal $\mathrm{CH}_{3}$ protons (triplet; $0.88 \mathrm{ppm}$ ) of the butyl segment and those related to the dimethylsiloxane repeating unit (singlet; $0.07 \mathrm{ppm}$ ). For allyl-PEO, the ratio between the signals originating from the $=\mathrm{CH}_{2}$ (two doublets; $5.17+5.19$ and $5.25+5.30 \mathrm{ppm}$ ) and EO (triplet; $3.65 \mathrm{ppm}$ ) functionalities was used. The amount of (diacetylated) polyether side product in acetylated allyl-PE was quantified by the peak ratio of the same $=\mathrm{CH}_{2}$ protons and the acetyl $\left(\mathrm{CH}_{3}\right)$ unit (singlet; $\left.2.08 \mathrm{ppm}\right)$.

Matrix Assisted Laser Desorption/Ionization Time of Flight Mass Spectroscopy (MALDI-ToF-MS) was also employed to determine the number and weight average molar mass $M_{\mathrm{n}}^{\mathrm{MALDI}}$ and $M_{\mathrm{w}}^{\mathrm{MALDI}}$ as well as the dispersity $\oslash\left(=M_{\mathrm{n}}^{\mathrm{MALDI}} / M_{\mathrm{w}}^{\mathrm{MALDI}}\right)$ of the prepared polymers, using a PerSeptive Biosystems Voyager-DE STR equipped with a $337 \mathrm{~nm}$ nitrogen laser ( $3 \mathrm{~ns}$ pulse). Spectra were recorded in positive ion and reflector mode with an accelerating potential of $20 \mathrm{kV}$. Polymers were dissolved in nonstabilised THF $\left(10 \mathrm{mg} \mathrm{mL}^{-1}\right)$ and mixed with a matrix solution (THAP, $40 \mathrm{mg} \mathrm{mL}^{-1}$ in THF) and an ionization agent (KTFA, $5 \mathrm{mg} \mathrm{mL}^{-1}$ in THF) in a 4:1:4 volume ratio. Allyl-PE polymers could be directly measured in MALDI-ToF MS, for PDMS-H a small EO-based "marker" had to be connected to the polymer chain to improve detectability. To do so, $2.00 \mathrm{~g}$ (0.67 mmol) PDMS-H 3000 was mixed with $0.106 \mathrm{~g}$ (0.73 mmol) 2-allyloxy ethyl acetate (prepared from 2-allyloxyethanol using the acetylation method for allyl-PE described above) and dissolved in $2.4 \mathrm{~mL}(2.1 \mathrm{~g})$ xylene and well stirred at room temperature. To this mixture, $2.1 \mu \mathrm{L}(0.05 \mathrm{wt} \%)$ Karstedt's catalyst was added using a micropipette, after which the temperature was increased to $100^{\circ} \mathrm{C}$. After $1 \mathrm{~h}$, the solution was filtered and the solvent removed in vacuo at $130^{\circ} \mathrm{C}$.

X-ray Photoelectron Spectroscopy (XPS) measurements were performed on a Thermo Scientific K-Alpha XPS spectrometer using a monochromated $\mathrm{Al} \mathrm{K} \alpha \mathrm{X}$-ray source $(E=1486.6 \mathrm{eV})$ operating at $72 \mathrm{~W}$. A circular area with a diameter of $400 \mu \mathrm{m}$ was probed with each measurement and a co-axial electron beam was active during all measurements for charge compensation. Angle-resolved XPS (ARXPS) measurements were done at sample tilt angles of $70^{\circ}$ to $0^{\circ}$ with $10^{\circ}$ intervals. Depth profiling was achieved by sequential etching of the sample using an $\mathrm{Ar}^{+}$gas cluster ion beam $(E=200 \mathrm{eV})$ for $10 \mathrm{~s} . \mathrm{C}_{1 \mathrm{~s}}, \mathrm{O}_{1 \mathrm{~s}}$, $\mathrm{N}_{1 \mathrm{~s}}$ and $\mathrm{Si}_{2 \mathrm{p}}$ lines were measured at a binding energy value of 285,532 , 400 and $102 \mathrm{eV}$ respectively (spectral width $20 \mathrm{eV}$ ). For angle-resolved XPS measurements, the electron detector was set to sequentially measure segments of the energy spectrum ("scanning mode") at $0.1 \mathrm{eV}$ intervals and a pass energy of $50 \mathrm{eV}$. For depth profiling, the detector was set to fully contain the required energy range ("snapshot mode") at pass energy of $150 \mathrm{eV}$. Data was recorded using the Avantage software and then processed with the CasaXPS software, which automatically calculated the percentage atomic concentration $X_{i}$ using

$X_{i}=100 \frac{A_{i}}{\sum_{j=1}^{m} A_{j}}$,

in which $m$ is the total number of measurements and $A_{i}$ and $A_{j}$ are the adjusted intensities of measurements $i$ and $j$, determined via

$A_{i}=\frac{I_{i}}{T\left(E_{i}\right) R_{i} L_{i}}$,

where $I_{\mathrm{i}}$ is the measured intensity (with subtracted Shirley background [70]), $T\left(E_{i}\right)$ the transmission function of the instrumental operating mode at energy $E_{i}, R_{i}$ the relative sensitivity factor of each individual spectral line $\left(\mathrm{C}_{1 \mathrm{~s}}=1.000, \mathrm{O}_{1 \mathrm{~s}}=2.881, \mathrm{~N}_{1 \mathrm{~s}}=1.676\right.$ and $\mathrm{Si}_{2 \mathrm{p}}=0.900$, obtained from the Avantage library) and $L_{i}$ the effective attenuation length (EAL) escape depth correction, computed using [71]

$L_{i}=\frac{0.65+0.007 E_{i}^{0.93}}{Z^{0.38}}$,

with $Z$ the atomic number. Angle-resolved (AR) and depth profiling (DP) measurements were performed on different size cut-outs of each individual sample (approximately $1.0 \times 0.5$ and $1.5 \times 1.5 \mathrm{~cm}^{2}$ for AR and DP, respectively). For each reported measurement a set of two samples (obtained from the same liquid formulation) was characterised. To address any potential difference between samples, selected formulations were prepared multiple times and characterised separately. The reported data is an average of each individual measurement (at a specific sample tilt angle or etching time, related to the average sample probing depth as discussed in Supplementary Information S2) with the error bar denoting the sample standard deviation.

Surface tension (SFT) measurements were carried out on a Dataphysics DCAT 21 tensiometer with a Wilhelmy plate (platinum-iridium, $w \times d \times h=19.9 \times 10 \times 0.2 \mathrm{~mm}^{3}$ ). Before each measurement, the plate was cleaned in butyl acetate, air dried and then heated in an open flame for several seconds. After cooling down, the probe was positioned on the liquid surface and the force acting on the plate (initial immersion depth $2 \mathrm{~mm}$ ) was measured with the corresponding SFT value automatically calculated using the SCAT software. Data was continuously recorded for $3 \mathrm{~min}$ (one measurement per second) and the average SFT was calculated by a linear fit through the data between $t=60$ and $180 \mathrm{~s}$ and extrapolation to $t=0 \mathrm{~s}$. Each liquid formulation was characterised twice and the obtained SFT value was averaged, with the error bar denoting 
the sample standard deviation. Selected formulations were prepared multiple times, in which case the SFT value reported is the average over all measurements performed and the error bar the sample standard deviation between the individual average values of each sample.

Water contact angle (CA) measurements were performed on a Dataphysics OCA30 contact angle goniometer. A $2 \mu \mathrm{L}$ droplet milliQ water was deposited on the coating surface and after approximately $2 \mathrm{~s}$ the contact angles were determinedby fitting of the contour of the droplet using the OCA20 software. At least four randomly positioned spots were probed per sample and the CA value was averaged from all individual left and right CA values. For each reported measurement a set of at least two samples (obtained from the same liquid formulation) was characterised. Selected formulations were prepared and characterised separately a multitude of times, in which case the reported CA value and error bar are respectively the average and sample standard deviation of all individual sample averages.

\section{Results and discussion}

\subsection{Preparation and characterisation of polydimethylsiloxane-polyether block copolymers}

Polydimethylsiloxane-poly(ethylene oxide) (PDMS-PEO) diblock copolymers with varying molar mass were prepared as shown in Fig. 1. Polydimethylsiloxane-poly(propylene oxide) (PDMS-PPO) copolymers were obtained in an analogous way. PDMS-H with a molar mass of 1000 , 3000 and $5000 \mathrm{~g} \cdot \mathrm{mol}^{-1}$ was synthesized via the polymerization of $\mathrm{D}_{3}$, initiated by n-BuLi and functionalization with DMCS. The absence of a polar solvent during the initiation stage allows accurate control over molar mass and dispersity suppressing chain propagation. [72] Complete conversion of the $\mathrm{D}_{3}$ monomer was confirmed using ${ }^{1} \mathrm{H}$ NMR and the disappearance of a signal at $0.17 \mathrm{ppm}$ (Fig. 2a). Furthermore, the presence of the silane proton at $4.71 \mathrm{ppm}$ and quantitative agreement with the butyl segment peak area indicated the successful functionalization of the macromer.

The exact molar mass of the prepared polymers was determined with ${ }^{1} \mathrm{H}$ NMR using the peak area ratio between siloxane and butyl segment signals. However, this method quickly becomes prone to deviations as the molar mass is increased and the siloxane peak broadens and overlaps with adjacent signals. Matrix Assisted Laser Desorption/Ionization Time of Flight Mass Spectrometry (MALDI-ToF-MS) has been used to successfully characterise low molar mass PDMS [72-75], but full quantitative analysis is often hindered by poor signal-to-noise ratios. By functionalizing the silicone macromer with a small, highly ionizable EO group, the MALDI signal intensity could be significantly improved. This was achieved via pre-reaction of PDMS-H with 2-allyloxy ethyl acetate (EOAc) using a similar method as for the final block copolymer hydrosilylation. The MALDI spectrum of PDMS 3000-EOAc is shown in Fig. 3 as an example. A characteristic three-peak pattern is observed, which originates from the polymerization mechanism. Upon addition of n-BuLi to a solution of $\mathrm{D}_{3}$ in cyclohexane, the polymerization is initiated via opening and subsequent fragmentation of a single $\mathrm{D}_{3}$ ring into three butyl-dimethylsiloxane-lithium species. [76] The resulting $-\mathrm{O}^{-} \mathrm{Li}^{+}$ complex is however stable enough to prevent immediate reaction of the negatively charged oxygen functionality with additional $\mathrm{D}_{3}$ monomers. Only after addition of THF, the charges of both ions are sufficiently separated to allow propagation to occur until all monomer has been consumed. [77] Following termination of the still reactive chains ends with DMCS, the major polymer species present should thus each be composed of $3 n+1$ dimethylsiloxane (D) repeating units, with $n$ being a positive integer. This assumption is confirmed by the MALDI-ToF-MS results, where the most intense peaks each correspond to the species mentioned, with a distance of $m / z=222$ (molecular mass of $D_{3}$ ) from one another. However, minor amounts of polymer species with $3 n$ and $3 n-1$ D repeating units at a distance of $m / z=74$ (molecular mass of D) are also detected, which is most likely a result of inter-molecular equilibration and intra-molecular backbiting reactions during the propagation step. Qualitatively similar results were observed before when MALDI-ToF-MS was used to investigate the molar mass distribution of PDMS prepared using anionic polymerization. [75]

After peak assignment of the MALDI spectra, the number average molar mass $M_{\mathrm{n}}^{\text {MALDI }}$ and weight-average molar mass $M_{\mathrm{w}}^{\text {MALDI }}$ were calculated via

$M_{\mathrm{n}}^{\mathrm{MALDI}}=\frac{\sum M_{i} N_{i}}{\sum N_{i}}$

and

$M_{\mathrm{w}}^{\mathrm{MALDI}}=\frac{\sum M_{i}^{2} N_{i}}{\sum M_{i} N_{i}}$

where $M_{i}$ is the mass and $N_{i}$ the number intensity of species $i$. The $M_{\mathrm{n}}^{\mathrm{MALDI}}, M_{\mathrm{w}}^{\mathrm{MALDI}}$ and dispersity $\oslash\left(=M_{\mathrm{n}}^{\mathrm{MALDI}} / M_{\mathrm{w}}^{\mathrm{MALDI}}\right)$ values determined for PDMS-H can be found in Table 1.

The endcapping of allyl-PEO with acetic anhydride was done to avoid a potential reaction between the silane and alcohol groups [78] during the final block coupling, which could result in triblock structures being formed, as well as to prevent addition of the final diblock copolymer to the isocyanate crosslinker during curing of the coating network. Full conversion of the hydroxyl functionality was verified using ${ }^{1} \mathrm{H}$ NMR<smiles>CCCC(C)(C)[Si](C)(C)O[Si](C)(C)CC</smiles>

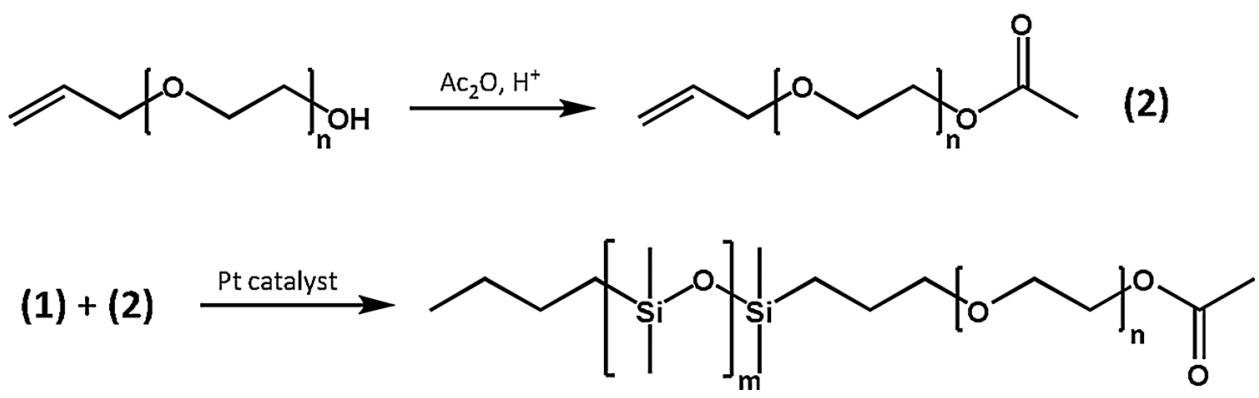

Fig. 1. Overview of the synthesis pathway employed to prepare well-defined polydimethylsiloxane-polyether diblock copolymers. 


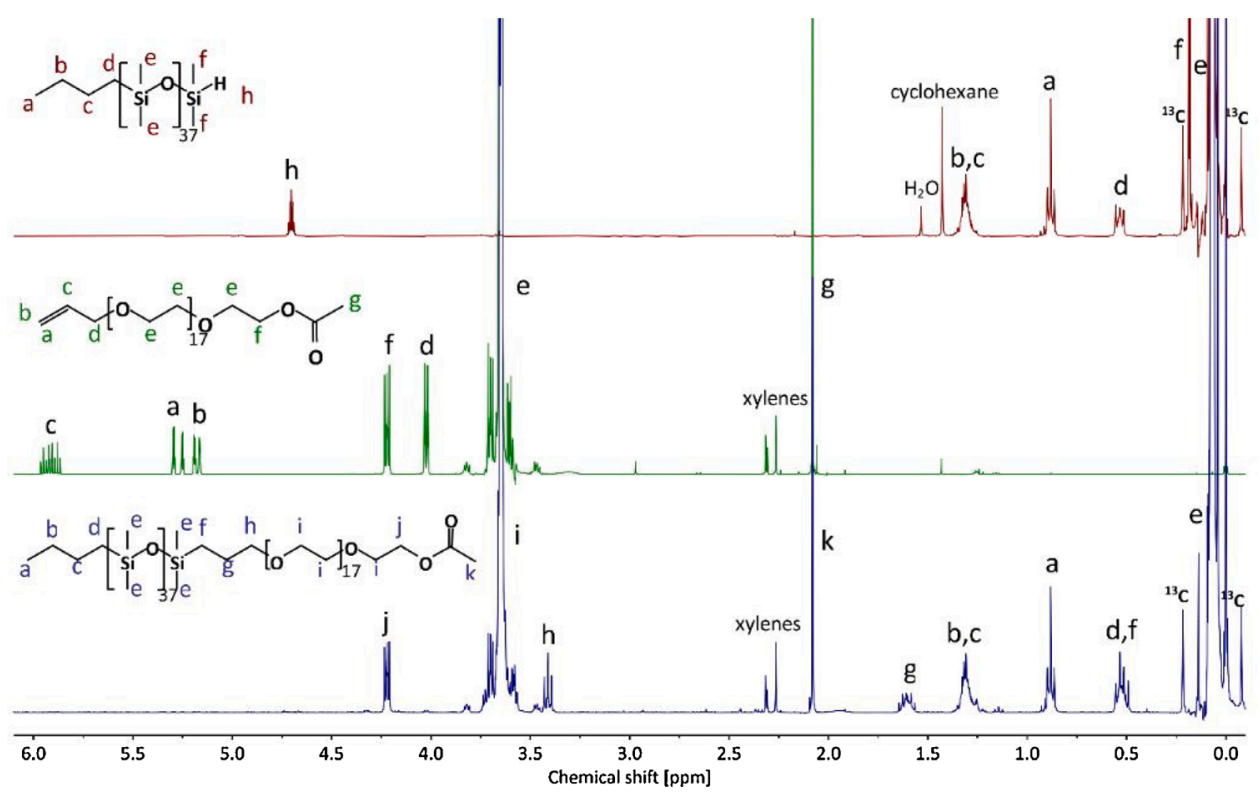

Fig. 2. ${ }^{1} \mathrm{H}$ NMR spectra of PDMS-H 3000 (top), allyl-PEO 900-Ac (middle) and PDMS 3000-PEO 900 block copolymer (bottom). Solvent CDCl ${ }_{3}$, reference TMS $(\delta$ $=0 \mathrm{ppm}$ ).
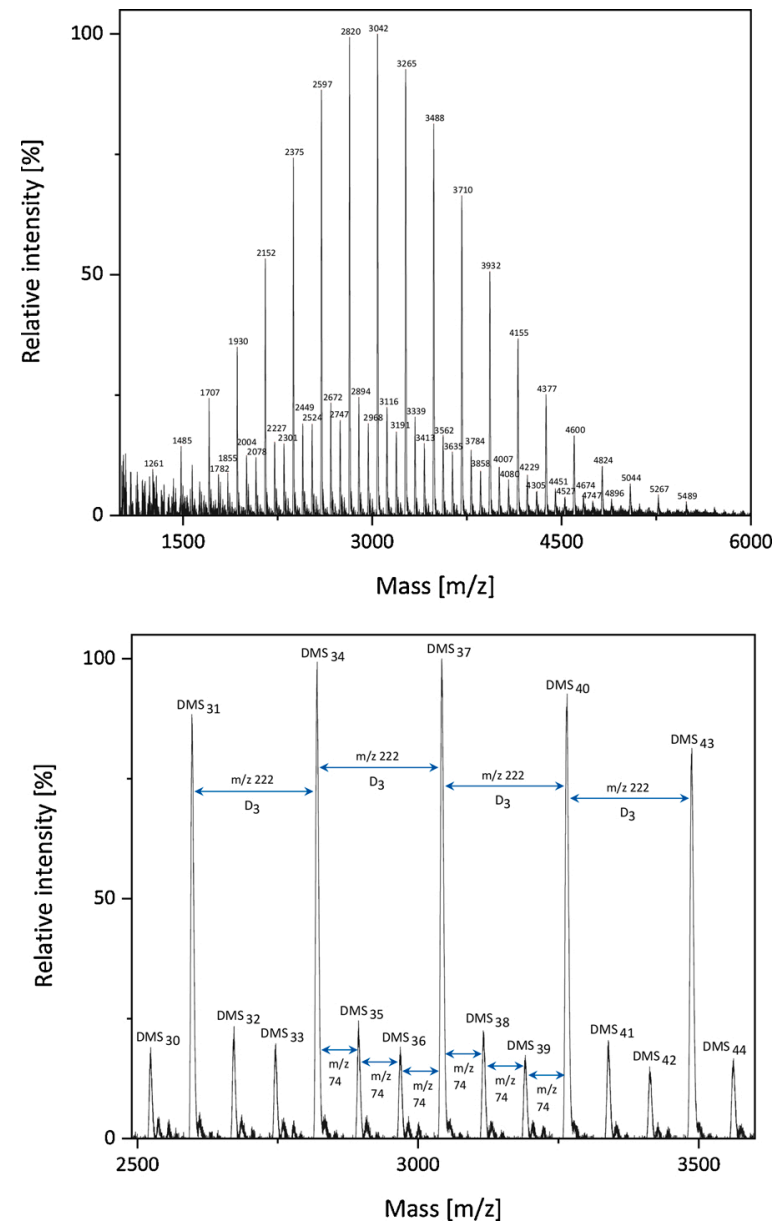

Fig. 3. MALDI-ToF-MS spectrum of PDMS 3000-EOAc. Full spectrum with peak $m / z$ values (top) and enlarged around $m / z=3000$ (bottom) with details and peak labelling.
Table 1

Analysis results for PDMS-H, allyl-PEO-Ac and allyl-PPO-Ac.

\begin{tabular}{lllll}
\hline Polymer & & $M_{\mathrm{n}}\left[\mathrm{g} \cdot \mathrm{mol}^{-1}\right]$ & $M_{\mathrm{w}}\left[\mathrm{g} \cdot \mathrm{mol}^{-1}\right]$ & $D[-]$ \\
\hline PDMS-H & 1000 & $1060^{\mathrm{a}}$ & - & - \\
& 3000 & $2870^{\mathrm{b}}$ & $3070^{\mathrm{b}}$ & 1.07 \\
Allyl-PEO-Ac & 5000 & $4870^{\mathrm{b}}$ & $5040^{\mathrm{b}}$ & 1.04 \\
& 500 & $480^{\mathrm{a}}$ & - & - \\
& 900 & $890^{\mathrm{b}}$ & $930^{\mathrm{b}}$ & 1.04 \\
Allyl-PPO-Ac & 1300 & $1270^{\mathrm{b}}$ & $1300^{\mathrm{b}}$ & 1.03 \\
& 500 & $520^{\mathrm{a}}$ & - & - \\
& 900 & $880^{\mathrm{b}}$ & $920^{\mathrm{b}}$ & 1.05 \\
& 1300 & $1240^{\mathrm{b}}$ & $1290^{\mathrm{b}}$ & 1.04 \\
\hline
\end{tabular}

${ }^{\mathrm{a} 1} \mathrm{H}-\mathrm{NMR}$.

${ }^{\mathrm{b}} \mathrm{MALDI}-\mathrm{ToF}-\mathrm{MS}$

(Fig. 2b) and the ratio between allylic and acetylic protons was successfully used to determine the amount of (diacetylated) PEO present in the product, a side product formed during the polymerization step due to the presence of small amounts of water. [79] For allyl-PEO this was determined to be between two and five percent depending on the respective molar mass and deemed to be acceptable when accounted for in the subsequent reaction step. For allyl-PPO however, PPO contents up to almost $30 \%$ were found and required further purification using centrifugation, assisted with extraction in water. With this relatively facile workup, PPO levels could be reduced to below $1 \%$ in most cases. MALDI-ToF-MS was employed to determine exact molar mass and dispersity of the acetylated polymers (See Table 1 and Supplementary Information Figure S1).

Addition of the silane group of PDMS-H to the double bond of allylPEO using Karstedt's catalyst provided the required diblock copolymer with full conversion of both precursors, as shown using ${ }^{1} \mathrm{H}$ NMR by the complete disappearance of both silane (4.71 ppm) and allyl (4.02+ $4.03,5.18+5.19,5.25+5.30$ and $5.92 \mathrm{ppm}$ ) signals and the formation of an additional carbon linker signal (1.61 ppm; Fig. 2c).

\subsection{PDMS-PE block copolymer segregation in coatings}

Synthesized PDMS-PEO and PDMS-PPO block copolymers were incorporated in a solvent-borne (butyl acetate) coating formulation commonly used for automotive applications and based on Macrynal ${ }^{\circledR}$ 
SM 515 and Desmodur ${ }^{\circledR}$ N 75. Applied layers were cured in an enclosed heating chamber, continuously flushed with nitrogen, to ensure controlled and reproducible curing conditions. Initial drying of the film was done at room temperature for $24 \mathrm{~h}$ to avoid the potential influence of increased curing kinetics or solvent evaporation on surfactant segregation. After a final heating step at $100{ }^{\circ} \mathrm{C}$ for $1 \mathrm{~h}$, no additional isocyanate consumption was observed with Fourier Transform Infrared Spectroscopy (FTIR). The glass transition temperature $T_{\mathrm{g}}$ of the crosslinked polymer film was measured using Differential Scanning Calorimetry (DSC) and estimated to be approximately $50{ }^{\circ} \mathrm{C}$. Apart from an increase in network crosslinking, heating the films to above $T_{\mathrm{g}}$ also allows the system to reach full equilibrium, unhampered by the glassy state of the network at room temperature. Surface PDMS concentration (see section below) is found to be unaffected by this heating step, which suggests that the segregated system already reaches equilibrium before full crosslinking.

Block copolymer segregation profiles with nanometre-scale depth resolution of the surface of cured films were obtained using a combination of angle-resolved and depth profiling XPS. The elemental composition of the coatings was evaluated layer-by-layer at specified sample tilt angles (ARXPS) followed by sequential $\mathrm{Ar}^{+}$etching. The correlation between these measurement conditions and coating depth probed is discussed in detail in Supplementary Information S2.

As an example, the elemental composition as a function of depth of a coating containing $0.1 \mathrm{wt} \%$ PDMS 3000-PEO 900 block copolymer is shown in Fig. 4. This data represents the combined angle-resolved and depth profiling XPS results of a single sample. Four different elements (C, O, Si and N) were detected which can be attributed to specific coating precursors. The silicon profile is of most interest, as it only originates from the block copolymer and thus directly can be correlated to the concentration of surfactant. Large segregation is indeed observed with significant concentrations of silicon detected near the coating-air interface, which quickly drops with increasing probing depth to a bulk value below the detection limit of XPS, approximately 0.1 atomic percent (at\%) [80]. Oxygen follows a similar trend, with a large contribution from the siloxane and ethylene oxide moieties, but levels off at a value of approximately 7 at $\%$ as the binder is also composed of monomers containing this element. The crosslinker is the sole component with nitrogen and a low concentration is observed at the film surface, which is highly enriched in surfactant. The nitrogen content increases with coating depth in a similar fashion as the silicon and oxygen concentration decreases. Finally, the concentration of carbon

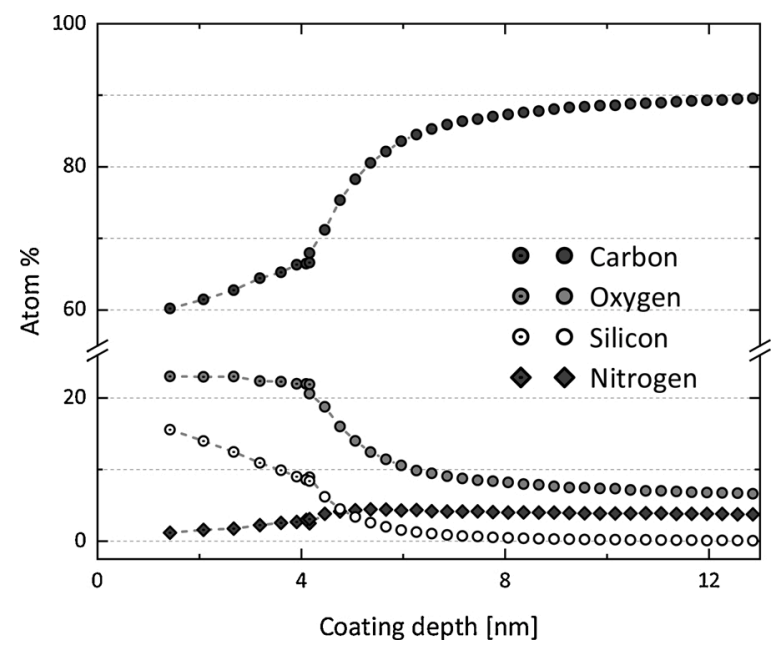

Fig. 4. Elemental (C, O, Si and $\mathrm{N}$ ) composition as a function of depth for a cured coating with PDMS 3000-PEO 900 block copolymer added (0.1 wt $\%$ overall concentration in the liquid coating formulation) obtained using XPS measurements. Atomic concentrations up to a depth of $4.16 \mathrm{~nm}$ (dotted symbols) were acquired using angle-resolved XPS. steadily increases as a function of probing depth accordingly.

Material surface properties are often determined by both the chemical and structural configuration of the top few nanometres. The elemental composition of this regime can be accurately quantified using ARXPS measurements at increased sample tilt angles, providing information about the extent of PDMS surface enrichment. Additional surface techniques are however required to obtain information about the resulting surface characteristics. Water contact angle (CA) and surface tension (SFT) analysis, of the cured and liquid coating formulation respectively, are complementary techniques able to probe the sample surface with the desired surface sensitivity. These three techniques were used to characterise the surface properties of a coating formulation as a function of PDMS 1000-PEO 500 bulk concentration, with an overview shown in Fig. 5.

The addition of only $0.0001 \mathrm{wt} \%$ already results in a surface silicon concentration of approximately $1 \mathrm{at} \% \mathrm{Si}$, indicating the high interfacial affinity of these block copolymers. Whereas the continued increase in segregation as a function of increasing block copolymer concentration in the formulation is relatively small, it starts to rise quickly from approximately $0.002 \mathrm{wt} \%$ onwards. After this strong increase, the surface enrichment starts to level off to full saturation (25 at $\% \mathrm{Si}$ ) at a formulation concentration of approximately $0.2 \mathrm{wt} \%$ and the surface layer remains highly enriched in PDMS from this point on. Water contact angle analysis provides a qualitatively similar result. Surface hydrophobicity is already enhanced significantly at minimal ( $<0.0005 \mathrm{wt} \%)$ block copolymer formulation concentration, with a gain in contact angle of 2 to $4^{\circ}$ compared to the nonfunctionalized surface. This value then seems to be relatively constant between $0.001 \mathrm{wt} \%$ and $0.01 \mathrm{wt}$, after which a strong increase is observed until approximately $0.2 \mathrm{wt} \%$ at which a CA value around $97^{\circ}$ is measured. When the block copolymer concentration is increased further, contact angles continue to rise slowly. The disparities between both methods at low block copolymer concentration confirm that the surface properties are not only a direct result of chemical functionalization, but are also affected by the structural characteristics of the surface-modifying agents. Whereas the water contact angle is initially measurably influenced by only minor block copolymer segregation at the interface, as evidenced by an increase of 2 to $3^{\circ}$ compared to the reference system, the effect of a further increase in surface concentration is negligible until a surface content of approximately 10 at $\% \mathrm{Si}$ has been reached. We believe that the small plateau in this concentration regime is the result of a competition for surface positioning between PDMS segments and apolar moieties from the binder system, where the block copolymer gradually replaces the binder in these positions as the concentration is increased. This removal of apolar binder segments therefore only results in a minor net change in surface hydrophobicity which only becomes apparent at sufficiently high PDMS concentration. From this point onwards, a clear increase in CA is observed coinciding with the measured increase in silicon content.

The effect of PDMS positioning at the interface is also clearly visible at high block copolymer concentrations (above $0.2 \mathrm{wt} \%$ ), where XPS shows a practically fully enriched surface ( 25 at $\% \mathrm{Si}$ ) over the full concentration range, yet CA values continue to increase slowly. It was observed that this rise in surface hydrophobicity is accompanied by a gradual and visual increase in film turbidity. At these block copolymer concentrations, incompatibility issues with the coating bulk arise and (macroscopic) phase separation starts to occur. CA measurements in this regime are therefore likely to be affected by this phase separation and the structural and chemical inhomogeneity by which it is accompanied. We have previously also shown that surface reorganization of a crosslinked polymer network with PDMS dangling chains is readily induced by water and that this process is often fast enough to have a measurable effect on water contact angle measurements. [81,82] Similar findings were reported by Tezuka et al. [83,84] for polysiloxane-polyurethane films, where environment-induced rearrangements in surface composition were found to occur within minutes. Unbound segregated low surface energy polymer chains in a crosslinked matrix should show 


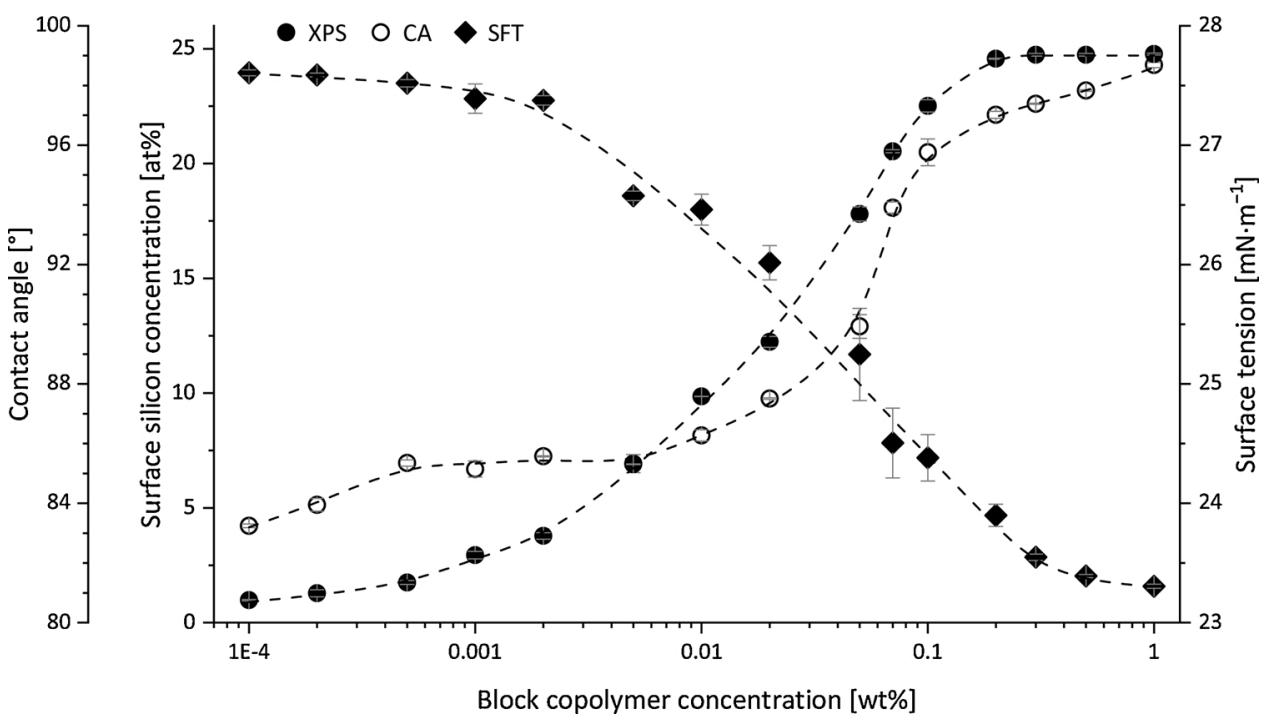

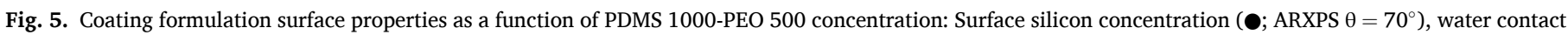

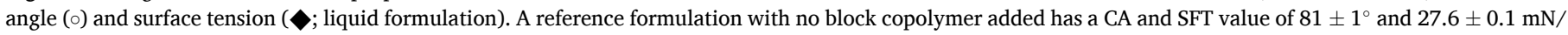
$\mathrm{m}$ respectively. The dashed lines are drawn to guide the eye.

similar behaviour and as a consequence CA analysis would generally probe a local partially 'de-segregated' surface. At high block copolymer concentrations, where the surface is fully enriched in silicone, the water contact angle measured is still 10 to $15^{\circ}$ lower compared to values reported for PDMS surfaces [85]. As a reference, crosslinked PDMS films with two different PDMS molar masses of 6000 and $17,200 \mathrm{~g} \cdot \mathrm{mol}^{-1}$ were prepared following the procedure described by us elsewhere [86] and provided contact angles of $106^{\circ}$ and $108^{\circ}$, respectively. The lower values found for the segregated coating systems therefore cannot be explained by the possible influence of PDMS chain characteristics alone, but are largely the result of fast surface reorientation or restructuring induced by the water droplet.

Tensiometry analysis of the liquid formulation presents a more continuous decrease of the surface tension over the entire concentration range measured, analogous to the surface enrichment as measured using ARXPS. The effect of a low block copolymer overall concentration on the surface tension is minimal and a decrease in SFT value is only observed from approximately $0.002 \mathrm{wt} \%$ onwards. This decrease is continued until a formulation concentration of approximately $0.3 \mathrm{wt} \%$ is reached after which it levels off to a steady value. The surface tension value measured at high block copolymer concentration is about $23.5 \mathrm{mN} / \mathrm{m}$, significantly higher than the surface energy of PDMS itself $(19.8 \mathrm{mN} / \mathrm{m})$ [87]. The further reduction in SFT indicates that there is a discrepancy between the coverage of the liquid and cured surfaces, and that further segregation occurs in the applied film during drying. This is also evidenced by the absence of a small plateau at intermediate block copolymer concentrations which was observed for the water contact angle. Possible competition between PDMS segments and apolar binder components for surface positioning is much less pronounced in the highly mobile, noncured liquid state. A distinct change in the slope is not observed either until a concentration of $0.3 \mathrm{wt} \%$. Such a change is commonly attributed to reaching the critical aggregation concentration (CAC). In our case the maximum solubility of the block copolymer has been reached at this point, which is evidenced by the formation of a turbid mixture. The resulting slight phase separation of the system is accompanied by a limitation in surface enrichment and hence a levelling of the curve. Although there is some scatter in the obtained data, the error of individual points is generally small, indicating that the Wilhelmy plate method is a viable technique to characterise the liquid surface even though real equilibrium is not achieved during measurement (see Supplementary Information S3). Butyl acetate was found to be a nonselective solvent for PDMS-PEO block copolymers due to the lack of surface activity of the amphiphilic molecules in this medium; a reduction in surface tension of a solution of PDMS 1000-PEO 500 in this medium was virtually non-existent and the minor differences at high concentration can be explained as a result of miscibility (Figure S 3.2). In fact, it was observed that copolymers with longer PDMS blocks dissolved to a higher extent; the solubility of PDMS is larger than that of PEO in butyl acetate. The absence of surfactant-like behaviour of these block copolymers in the solvent indicates that micellar aggregates are likely not formed in the liquid coating formulation either. The PDMS block does however seem to induce surface affinity in the coating mixture as the reduction in surface tension is much more prominent compared to the butyl acetate solution. Apparently, the presence of the binder system directly drives the interfacial segregation of the block copolymer due to the incompatibility of the PDMS segment. The molecular design of the surface-active polymer should thus directly affect the extent of segregation and resulting coating surface characteristics.

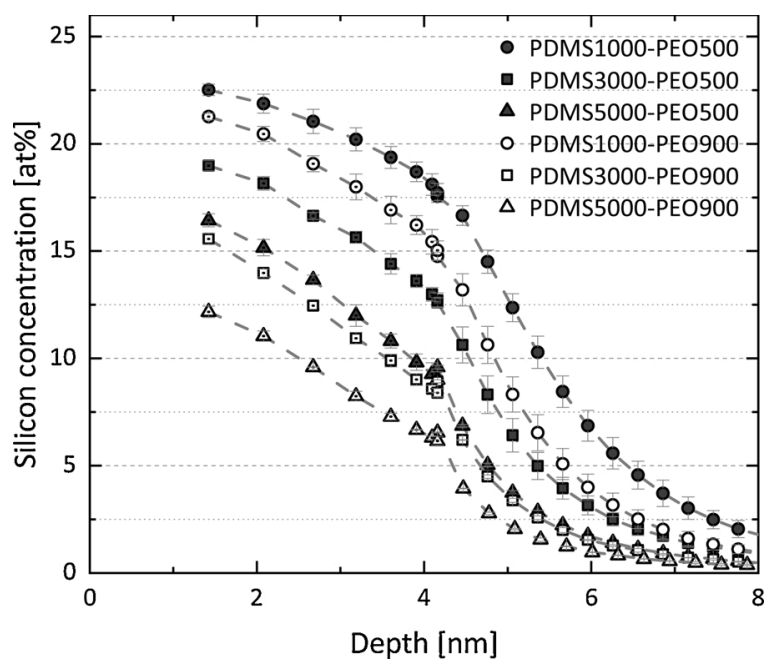

Fig. 6. PDMS-PEO block copolymer concentration profiles in a cured coating ( 0.1 wt $\%$ overall concentration in the liquid coating formulation) obtained using XPS measurements. Values up to a depth of $4.16 \mathrm{~nm}$ were acquired using angle-resolved XPS. The dashed lines are drawn to guide the eye. 


\subsection{Influence of molecular architecture on segregation behaviour}

The surface segregation of PDMS-PEO block copolymers with varying block lengths is presented in Fig. 6. All surfactants show considerable segregation and values close to full surface coverage (25 at $\% \mathrm{Si}$ ) are observed for PDMS 1000-PEO 500. Increments in silicone block size evidently result in reduced segregation and surface enrichment, despite the higher surface affinity that would be expected for these compounds. We believe that this is a result of the relatively high concentration $(0.1$ $\mathrm{wt} \%$ ) in the formulation, so that incompatibility issues arise between the block copolymer and coating matrix, in turn resulting in local phase separation and hence a reduction in surface enrichment of the siloxane block. [88] Measurements at a considerably lower block copolymer concentration will be performed to verify this hypothesis. The behaviour observed seems to be analogous with that found in previous work on surface tension measurements of PDMS-PEO block copolymers in aqueous systems [89], which also shows that surfactants with lower DMS content present an increase in surface excess concentration and a stronger reduction in surface tension as a result. Similar results are also found for related triblock surfactants in aqueous media [43].

The silicon concentration profiles in Fig. 6 also show that PEO block size, in comparison to PDMS, has only a limited effect on segregation behaviour, as only slightly lower surface enrichment is observed as the polar block size is increased from 500 to $900 \mathrm{~g} \cdot \mathrm{mol}^{-1}$. This small decrease can be readily attributed to a slight improvement in compatibility of the copolymer with the coating matrix. Increasing the molar mass further to $1300 \mathrm{~g} \cdot \mathrm{mol}^{-1}$ shows only a minor reduction in silicon surface concentration in combination with PDMS1000 and practically no effect with larger siloxane molar masses (Figure S4). Segregation of amphiphilic PDMS-PEO polymers is thus mainly driven by the incompatibility of the apolar block and binder system, where a short PDMS segment is most effective at functionalizing the film surface and an increase in molar mass negatively impacts segregation. PEO length can be used to further fine-tune surface enrichment via a slight change in compatibility as the polar block size is adjusted. Interactions between the block copolymer and coating matrix are directly regulated by the polyether block [90]. Exchanging the PEO segment with more apolar PPO units therefore changes the overall compatibility of the surfactant and allows for further direction of the extent of surface segregation.

Fig. 7 provides an overview of the segregation behaviour of selected PDMS-PPO block copolymers. It is immediately evident that lower silicon surface concentration values are observed and that the relation with PDMS length for these more apolar polymers is not as apparent as for the PDMS-PEO copolymers. Specifically, PDMS-PPO block copolymers based on PDMS 1000 exhibit a much lower surface enrichment than their PDMS-PEO counterparts. For PDMS-PPO, increasing PDMS mass to
$3000 \mathrm{~g} \cdot \mathrm{mol}^{-1}$ improves segregation measurably, after which a similar or slightly lower surface enrichment is observed for PDMS 5000-based polymers. This indicates that incorporation of PPO provides block copolymers with increased compatibility with the coating matrix. The stronger affinity of PPO for the binder is especially apparent for PDMS 1000 -PPO 1300, where the relatively long polyether is able to suppress the surface affinity of the short silicone chain. PPO chain length seems to have a negligible effect on segregation in combination with PDMS 3000 and 5000 and concentration profiles of block copolymers based on PPO 500 are evidently somewhat less well-defined than for PPO 1300. It can be concluded that interactions with the binder play an important role on surfactant segregation and in optimizing coating formulations and resulting surface functionalities.

Surface tension and water contact angle values of liquid and cured coating formulations with $0.1 \mathrm{wt} \%$ added PDMS-PPO block copolymer for the various molar masses are presented in Fig. 8 and Fig. 9 respectively. Surface tension measurements are in good qualitative agreement with the surface enrichment trends obtained using XPS discussed before. As PDMS block mass is increased from 1000 to $3000 \mathrm{~g} \cdot \mathrm{mol}^{-1}$, the surface tension values are reduced, indicating a higher enrichment of surfactant on the liquid surface. An additional increase in PDMS molar mass to $5000 \mathrm{~g} \cdot \mathrm{mol}^{-1}$ does not have any significant effect and the surface

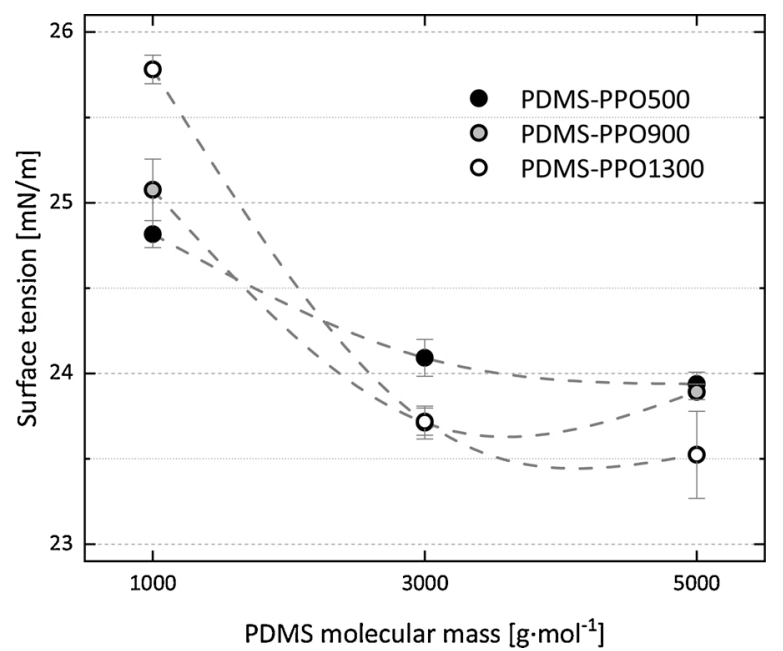

Fig. 8. Surface tension of liquid coating formulations containing $0.1 \mathrm{wt} \%$ PDMS-PPO block copolymer. A formulation without block copolymer has a surface tension value of $27.6 \pm 0.1 \mathrm{mN} \cdot \mathrm{m}^{-1}$. The dashed lines are drawn to guide the eye. a)

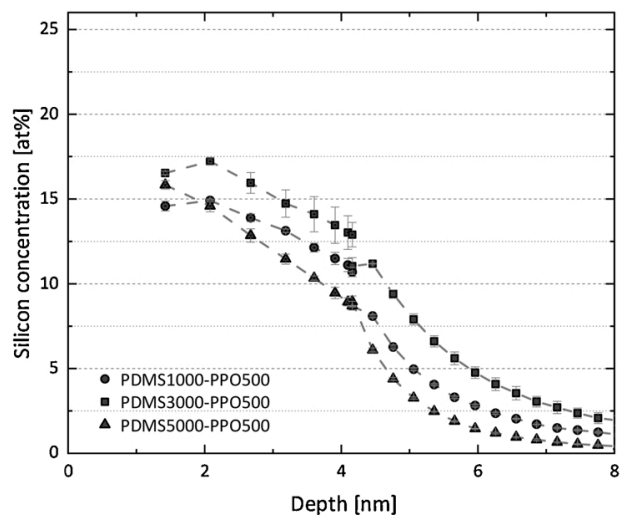

b)

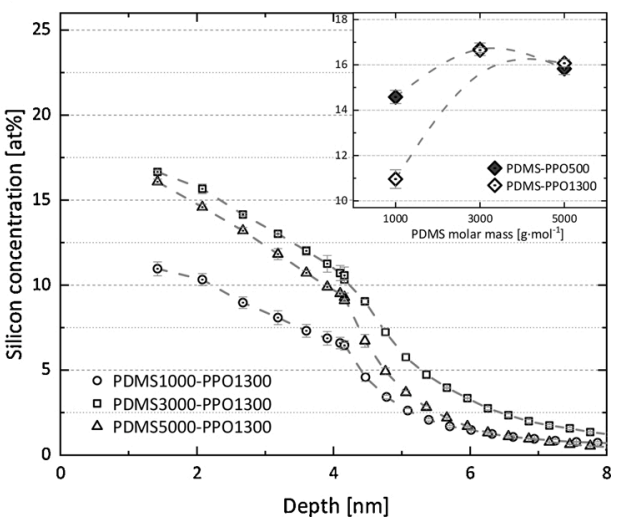

Fig. 7. (a) PDMS-PPO500 block copolymer concentration profiles in a cured coating ( $0.1 \mathrm{wt} \%$ overall concentration in the liquid coating formulation) obtained using XPS measurements. Values up to a depth of $4.16 \mathrm{~nm}$ were acquired using angle-resolved XPS. (b) Concentration profiles of PDMS-PPO1300. Inset: Surface silicon concentration values obtained using angle-resolved XPS measurements at a sample tilt angle of $70^{\circ}$. The dashed lines are drawn to guide the eye. 


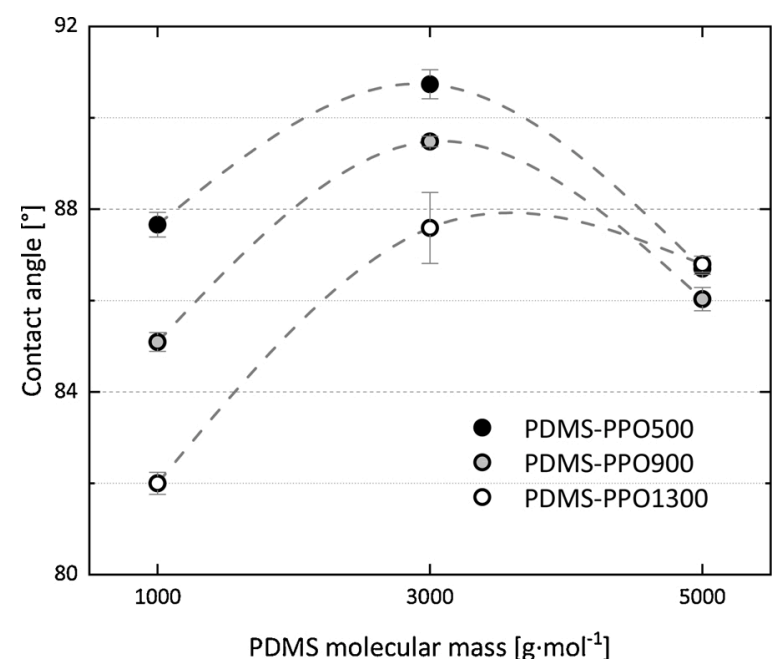

Fig. 9. Water contact angle of cured coating formulations containing PDMSPPO block copolymer $(0.1 \mathrm{wt} \%$ overall concentration in the liquid coating formulation). A formulation without block copolymer has a contact angle value of $81 \pm 1^{\circ}$. The dashed lines are drawn to guide the eye.

tension remains practically constant. Contact angle measurements are in good qualitative agreement with the ARXPS results (Fig. 7, inset) and show that surface hydrophobicity in this case can be almost directly translated from the concentration of PDMS on the surface. The length of the apolar block seems to assert some influence on the CA value when combined with smaller PPO segments, but the effect is diminishing as PDMS block size is increased and the surfaces of coating formulations containing PDMS 5000-PPO surfactants show virtually identical hydrophobicity irrespective of the PPO molar mass. Surface property data for coating formulations containing PDMS-PEO block copolymers are given in Supplementary Information S5. In contrary to PDMS-PPO, no clear trends could be observed for the PEO-based amphiphiles. Most values are found to be around $24 \mathrm{mN} / \mathrm{m}$, similar to those of PDMS-PPO with larger PDMS block lengths. Water contact angle measurements also resulted in somewhat scattered data, although surfaces coated with PDMS-PEO were generally found to be more hydrophobic than when PDMS-PPO was used. The more apolar character in this case is directly a result of the larger segregation of PDMS-PEO block copolymers and resulting increased PDMS concentration on the surface, in accordance with the XPS results shown before.

\section{Conclusions}

Well-defined block copolymers composed of polydimethylsiloxane and poly(ethylene oxide) or poly(propylene oxide) were successfully prepared via a stepwise synthesis method. Block copolymers with varying individual block molar mass and chemical nature of the polyether block were incorporated in a model coating formulation, solventborne in butyl acetate. It was shown that the molecular design of the block copolymer significantly affected the segregation behaviour and can be used to precisely tune the resulting surface properties.

Mono silane-terminated PDMS, synthesized via anionic polymerization of $\mathrm{D}_{3}$, was coupled to PEO or PPO mono allyl ether via a hydrosilylation reaction and all products were characterised via ${ }^{1} \mathrm{H}$ NMR and MALDI-ToF-MS. The segregation behaviour of various block copolymers with different molar masses was investigated via a combination of angleresolved and depth profiling XPS. In addition, the surface properties of liquid and cured coating formulations were investigated using contact angle and surface tension measurements. PDMS-PEO block copolymers were observed to be extremely surface active, with significant concentrations of silicon detected in the top few $\mathrm{nm}$ of the cured coating layer at only minimal concentration in the formulation. The presence of low surface energy PDMS at the film surface was further verified via an observed decrease in surface tension and an increase in contact angle of the liquid and cured film, respectively. PDMS 1000-PEO 500 surface enrichment was enhanced by an increase in formulation concentration, until full coverage of the cured film surface (as evidenced by XPS) at a concentration of approximately $0.2 \mathrm{wt} \%$. However, the surface tension of the liquid formulation decreases moderately with increasing block copolymer concentration from this point on, indicating the discrepancy between surface enrichment in the liquid and cured state. For PDMSPEO block copolymers, at a formulation concentration of $0.1 \mathrm{wt} \%$, an increase in PDMS block molar mass from 1000 to 3000 and 5000 $\mathrm{g} \cdot \mathrm{mol}^{-1}$ resulted in a measurable decline in segregation. A change in PEO block molar mass from 500 to $900 \mathrm{~g} \cdot \mathrm{mol}^{-1}$ in turn reduced surface enrichment even further, but an additional increase to $1300 \mathrm{~g} \cdot \mathrm{mol}^{-1} \mathrm{did}$ not have any significant effect on PDMS surface enrichment. The lower surface segregation of PDMS-PPO was attributed to the increased compatibility of PPO with the binder system. In this case, the largest segregation and most distinct changes in surface properties (i.e. a decrease in surface tension and increase in water contact angle of the liquid and cured formulations, respectively) were observed for PDMS3000-based block copolymers, with especially PDMS 1000-PPO being relatively ineffective as compared to its PDMS-PEO counterparts.

\section{Declaration of Competing Interest}

The authors declare that they have no known competing financial interests or personal relationships that could have appeared to influence the work reported in this paper.

\section{Acknowledgements}

The authors would like to thank ALTANA AG (Wesel, Germany) for support to the SEGADD project, and Dr. Christian Schaumberg (ALTANA AG, Wesel, Germany) and Dr. Guillaume Jaunky (BYK-Chemie GmbH, Wesel, Germany) for helpful advice, valuable comments on various technical issues and assistance with this project.

\section{Appendix A. Supplementary data}

Supplementary material related to this article can be found, in the online version, at doi:https://doi.org/10.1016/j.porgcoat.2020.105991

\section{References}

[1] J. Bieleman, Additives for Coatings, Wiley-VCH, 2000.

[2] G. de With, Polymer Coatings: Guide to Chemistry, Characterization and Selected Applications, Wiley-VCH, 2018.

[3] J.T. Koberstein, J. Polym. Sci. Part B: Polym. Phys. 42 (2004) 2942-2956.

[4] T. Maruyama, Soft Nanomaterials, 19, World Scientific Publishing Co., 2019, pp. 167-174, ch. 6.

[5] G.E. Stein, T.S. Laws, R. Verduzco, Macromolecules 52 (2019) 4787-4802.

[6] N.M. Patel, D.W. Dwight, J.L. Hedrick, D.C. Webster, J.E. McGrath, Macromolecules 21 (1988) 2689-2696.

[7] M.M. Gorelova, V.Y. Levin, I.L. Dubchak, A.A. Zhdanov, L.I. Makarova, I. P. Storozhuk, S.S. Koroleva, Polymer Science U.S.S.R. 31 (1989) 643-649.

[8] I. Yilgor, W.P. Steckle, E. Yilgor, R.G. Freelin, J.S. Riffle, J. Polym. Sci. Part A: Polym. Chem. 27 (1989) 3673-3690.

[9] M.M. Gorelova, A.J. Pertsin, V.Y. Levin, L.I. Makarova, L.V. Filimonova, J. Appl. Polym. Sci. 45 (1992) 2075-2078.

[10] A.J. Pertsin, M.M. Gorelova, V.Y. Levin, L.I. Makarova, J. Appl. Polym. Sci. 45 (1992) 1195-1202.

[11] X. Chen, J.A. Gardella, Macromolecules 27 (1994) 3363-3369.

[12] M.M. Gorelova, A.J. Pertsin, A.M. Muzafarov, O.T. Gritsenok, N.G. Vasilenko, J. Appl. Polym. Sci. 55 (1995) 1131-1135.

[13] M.M. Gorelova, A.J. Pertsin, I.O. Volkov, L.V. Filimonova, L.I. Makarova, A A. Zhdanov, J. Appl. Polym. Sci. 57 (1995) 227-231.

[14] W. Hu, J.T. Koberstein, J.P. Lingelser, Y. Gallot, Macromolecules 28 (1995) 5209-5214.

[15] J. Chen, J.A. Gardella, Macromolecules 31 (1998) 9328-9336.

[16] M.M. Gorelova, A.J. Pertsin, I.O. Volkov, N.B. Sanches, A.S. Gomes, J. Appl. Polym. Sci. 69 (1998) 2349-2356. 
[17] H. Lee, L.A. Archer, Macromolecules 34 (2001) 4572-4579.

[18] Y. Lee, I. Akiba, S. Akiyama, J. Appl. Polym. Sci. 87 (2003) 375-380.

[19] S. Rimdusit, W. Benjapan, S. Assabumrungrat, T. Takeichi, R. Yokota, Polym. Eng. Sci. 47 (2007) 489-498.

[20] S.L. Pesek, Y.-H. Lin, H.Z. Mah, W. Kasper, B. Chen, B.J. Rohde, M.L. Robertson, G. E. Stein, R. Verduzco, Polymer 98 (2016) 495-504.

[21] A. Camós Noguer, S.M. Olsen, S. Hvilsted, S. Kiil, Prog. Org. Coat. 106 (2017) 77-86.

[22] M. Horgnies, E. Darque-Ceretti, R. Combarieu, Prog. Org. Coat. 47 (2003) 154-163.

[23] M. Horgnies, E. Darque-Ceretti, Prog. Org. Coat. 55 (2006) 27-34.

[24] I. Yilgör, J.E. McGrath, Adv. Polym. Sci. 86 (1988) 1-86.

[25] A. Beaugendre, S. Degoutin, S. Bellayer, C. Pierlot, S. Duquesne, M. Casetta, M. Jimenez, Prog. Org. Coat. 110 (2017) 210-241.

[26] A. Vitale, S. Touzeau, F. Sun, R. Bongiovanni, Macromolecules 51 (2018) 4023-4031.

[27] P. Majumdar, D.C. Webster, Macromolecules 38 (2005) 5857-5859.

[28] P. Majumdar, A. Ekin, D.C. Webster, in: T. Provder, J. Baghdachi (Eds.), Smart Coatings, 957, 2007, pp. 61-75, ch. 5.

[29] R.J. Pieper, A. Ekin, D.C. Webster, F. Cassé, J.A. Callow, M.E. Callow, J. Coat. Technol. Res. 4 (2007) 453-461.

[30] S. Sommer, A. Ekin, D.C. Webster, S.J. Stafslien, J. Daniels, L.J. VanderWal, S. E. Thompson, M.E. Callow, J.A. Callow, Biofouling 26 (2010) 961-972.

[31] R.B. Bodkhe, S.E.M. Thompson, C. Yehle, N. Cilz, J. Daniels, S.J. Stafslien, M. E. Callow, J.A. Callow, D.C. Webster, J. Coat. Technol. Res. 9 (2011) 235-249.

[32] T.P. Galhenage, D.C. Webster, A.M.S. Moreira, R.J. Burgett, S.J. Stafslien, L. Vanderwal, J.A. Finlay, S.C. Franco, A.S. Clare, J. Coat. Technol. Res. 14 (2016) 307-322.

[33] A. Ekin, D.C. Webster, J.W. Daniels, S.J. Stafslien, F. Cassé, J.A. Callow, M. E. Callow, J. Coat. Technol. Res. 4 (2007) 435-451.

[34] Z. Chen, B. Chisholm, J. Kim, S. Stafslien, R. Wagner, S. Patel, J. Daniels, L.V. Wal, J. Li, K. Ward, M. Callow, S. Thompson, C. Siripirom, Polym. Int. 57 (2008) 879-886.

[35] J. Fang, A. Kelarakis, D. Wang, E.P. Giannelis, J.A. Finlay, M.E. Callow, J. A. Callow, Polymer 51 (2010) 2636-2642.

[36] S.K. Rath, J.G. Chavan, S. Sasane, Jagannath, M. Patri, A.B. Samui, B. C. Chakraborty, Appl. Surf. Sci. 256 (2010) 2440-2446.

[37] S.K. Rath, J.G. Chavan, T.K. Ghorpade, T. Umasankar Patro, M. Patri, J. Coat. Technol. Res. 15 (2018) 185-198.

[38] M.K. Sharma, Surface Phenomena and Additives in Water-Based Coatings and Printing Technology, Springer-Verlag, 1991.

[39] A. Bubat, W. Scholz, Chim. Int. J. Chem. 56 (2002) 203-209.

[40] D. Perry, in: G. Davison, B.C. Lane (Eds.), Additives in Water-Borne Coatings, 2003, pp. 77-84.

[41] F. Hostettler, patent DE1091324B, 1958.

[42] E.G. Schwarz, W.G. Reid, Ind. Eng. Chem. 56 (1964) 26-31.

[43] B. Kanner, W.G. Reid, I.H. Petersen, Ind. Eng. Chem. Prod. Res. Dev. 6 (1967) 88-92.

[44] T.C. Kendrick, B.M. Kingston, N.C. Lloyd, M.J. Owen, J. Colloid Interface Sci. 24 (1967) 135-140.

[45] R.M. Hill, Specialist Surfactants, Springer Science \& Business Media, 1997, pp. 143-168, https://doi.org/10.1007/978-94-009-1557-2, ch. 6.

[46] T.A. Thorstenson, J.B. Huang, M.W. Urban, K. Haubennestel, Prog. Org. Coat. 24 (1994) 341-358.

[47] M. Inutsuka, N.L. Yamada, K. Ito, H. Yokoyama, ACS Macro Lett. 2 (2013) 265-268.

[48] M. Inutsuka, H. Tanoue, Norifumi L. Yamada, K. Ito, H. Yokoyama, RSC Adv. 7 (2017) 17202-17207.

[49] H. Tanoue, M. Inutsuka, N.L. Yamada, K. Ito, H. Yokoyama, Macromolecules 50 (2017) 5549-5555.

[50] H. Tanoue, K. Inoue, N.L. Yamada, K. Ito, S. Miyao, T. Ishizone, H. Yokoyama, Soft Matter 14 (2018) 5930-5935.

[51] R. Murthy, C.D. Cox, M.S. Hahn, M.A. Grunlan, Biomacromolecules 8 (2007) 3244-3252.

[52] R. Murthy, B.M. Bailey, C. Valentin-Rodriguez, A. Ivanisevic, M.A. Grunlan, J. Polym. Sci. Part A: Polym. Chem. 48 (2010) 4108-4119.
[53] M.L. Hawkins, M.A. Rufin, J.E. Raymond, M.A. Grunlan, J. Mater. Chem. B 2 (2014) 5689-5697.

[54] M.A. Rufin, B.K.D. Ngo, M.E. Barry, V.M. Page, M.L. Hawkins, S.J. Stafslien, M. A. Grunlan, Green Mater. 5 (2017) 4-13.

[55] P.J. Cumpson, J. Electron Spectros. Relat. Phenomena 73 (1995) 25-52.

[56] C.J. Jalbert, J.T. Koberstein, R. Balaji, Q. Bhatia, L. Salvati, I. Yilgor, Macromolecules 27 (1994) 2409-2413.

[57] J.F. Watts, M.-L. Abel, C. Perruchot, C. Lowe, J.T. Maxted, R.G. White, J. Electron Spectros. Relat. Phenomena 121 (2001) 233-247.

[58] C. Perruchot, J.F. Watts, C. Lowe, R.G. White, P.J. Cumpson, Surf. Interface Anal. 33 (2002) 869-878.

[59] C. Perruchot, M.-L. Abel, J.F. Watts, C. Lowe, J.T. Maxted, R.G. White, Surf. Interface Anal. 34 (2002) 570-574.

[60] P.A.V. O'Rourke-Muisener, C.A. Jalbert, C. Yuan, J. Baetzold, R. Mason, D. Wong, Y.J. Kim, J.T. Koberstein, B. Gunesin, Macromolecules 36 (2003) 2956-2966.

[61] K.B. Walters, D.W. Schwark, D.E. Hirt, Langmuir 19 (2003) 5851-5860.

[62] A.A. El-Shehawy, H. Yokoyama, K. Sugiyama, A. Hirao, Macromolecules 38 (2005) 8285-8299.

[63] D.A. Wong, P.A.V. O'Rourke-Muisener, J.T. Koberstein, Macromolecules 40 (2007) 1604-1614.

[64] D. Wong, C.A. Jalbert, P.A.V. O'Rourke-Muisener, J.T. Koberstein, Macromolecules 45 (2012) 7973-7984.

[65] J.A. Mielczarski, E. Mielczarski, G. Galli, A. Morelli, E. Martinelli, E. Chiellini, Langmuir 26 (2010) 2871-2876.

[66] B.R. Yasani, E. Martinelli, G. Galli, A. Glisenti, S. Mieszkin, M.E. Callow, J. A. Callow, Biofouling 30 (2014) 387-399.

[67] E. Martinelli, E. Guazzelli, A. Glisenti, G. Galli, Coatings 9 (2019) 153.

[68] W. Jaunky, A. Frank, V. Wintermeyer and M. Michelbrink, patent WO 2017/ 037123 A1, 2017.

[69] U. Maschke, T. Wagner, X. Coqueret, Die Makromol. Chemie 193 (1992) 2453-2466.

[70] D.A. Shirley, Phys. Rev. B 5 (1972) 4709-4714.

[71] M.P. Seah, Surf. Interface Anal. 44 (2012) 497-503.

[72] A.M. Hawkridge, J.A. Gardella, J. Am. Soc. Mass Spectrom. 14 (2003) 95-101.

[73] G. Montaudo, M.S. Montaudo, C. Puglisi, F. Samperi, Rapid Commun. Mass Spectrom. 9 (1995) 1158-1163.

[74] E.P. Maziarz, X.M. Liu, E.T. Quinn, Y.-C. Lai, D.M. Ammon, G.L. Grobe, J. Am. Soc. Mass Spectrom. 13 (2002) 170-176.

[75] W. Yan, J.A. Gardella, T.D. Wood, J. Am. Soc. Mass Spectrom. 13 (2002) 914-920.

[76] C.L. Frye, R.M. Salinger, F.W.G. Fearon, J.M. Klosowski, T. DeYoung, J. Org. Chem. 35 (1970) 1308-1314.

[77] C.L. Lee, C.L. Frye, O.K. Johansson, Polymer preprints 10 (1969) 1361-1367.

[78] D.W. Chung, T.G. Kim, J. Ind. Eng. Chem. 13 (2007) 979-984.

[79] J. Herzberger, K. Niederer, H. Pohlit, J. Seiwert, M. Worm, F.R. Wurm, H. Frey, Chem. Rev. 116 (2016) 2170-2243.

[80] A.G. Shard, Surf. Interface Anal. 46 (2014) 175-185.

[81] A.C.C. Esteves, I.D. Günbas, J.M. van Riel, B.A.J. Noordover, G. de With, R.A.T. M. van Benthem, RSC Adv. 4 (2014) 20094-20101.

[82] Y. Zhang, F. Karasu, C. Rocco, L.G.J. van der Ven, R.A.T.M. van Benthem, X. Allonas, C. Croutxé-Barghorn, A.C.C. Esteves, G. de With, Polymer 107 (2016) $249-262$.

[83] Y. Tezuka, T. Ono, K. Imai, J. Colloid Interface Sci. 136 (1990) 408-414.

[84] Y. Tezuka, H. Kazama, K. Imai, J. Chem. Soc. Faraday Trans. 87 (1991) 147-152.

[85] A. Mata, A.J. Fleischman, S. Roy, Biomed. Microdevices 7 (2005) 281-293.

[86] A.C.C. Esteves, J. Brokken-Zijp, J. Laven, H.P. Huinink, N.J.W. Reuvers, M.P. Van, G. de With, Polymer 50 (2009) 3955-3966.

[87] D.W. van Krevelen, K. te Nijenhuis, Properties of Polymers, 4th edn., Elsevier, 2009.

[88] A. Camós Noguer, R. Latipov, F.B. Madsen, A.E. Daugaard, S. Hvilsted, S.M. Olsen, S. Kiil, Prog. Org. Coat. 120 (2018) 179-189.

[89] G. Kickelbick, J. Bauer, N. Huesing, M. Andersson, K. Holmberg, Langmuir 19 (2003) 10073-10076.

[90] S. Yamamoto, S. Kitahata, A. Shimomura, K. Tokuda, T. Nishino, T. Maruyama, Langmuir 31 (2015) 125-131. 